\title{
Impact of Active Route Time Out and Delete Period Constant on AODV Performance
}

\author{
Niraja Agrawal \\ SIRTS Bhopal
}

\author{
M. Fatima, $\mathrm{PhD}$ \\ SIRTS Bhopal
}

\begin{abstract}
Adhoc network is a collection of wireless mobile nodes, forming a network topology without the use of any existing infrastructure or centralised administration. MANET are being deployed to perform a number of tasks. MANETs has a large number of routing protocols. The AODV routing protocol meets efficiently with the ad-hoc network specification. In this paper AODV and DSR behaviour are studied.[1].Simulation result shows that AODV depends on route maintenance matrices ART (Active Route Timeout) and DPC(Delete Period Constant).AODV result varies with the change in ART and DPC .
\end{abstract}

\section{Keywords}

MANETs, AODV, DSR, Routing Protocols, ART(Active route timeout), DPC(Delete period constant)

\section{INTRODUCTION}

A mobile ad hoc network (MANET), is a dynamic distributed system of wireless mobile nodes in which the nodes can move arbitrarily, in any direction, independent of each other therefore the network can experience rapid and unpredictable topology changes [1].The mobile nodes can communicate with each other through direct wireless links or multi-hop routing. In other words, ad hoc networking allows devices to create a network on demand without prior coordination or configuration. Thus, nodes within a MANET are involved in routing and forwarding information between neighbours because nodes in a MANET normally have limited transmission ranges, some nodes cannot communicate directly with each other. Hence, routing paths contain multiple hops, and every node has the responsibility to act as a router. Figure 1.1, shows a general structure of MANET. MANETs have several operating constraints [2] such as limited battery charge per node, limited transmission range and limited bandwidth. Generally routes in MANETs are multi-hop in nature. Short-range MANET can simplify the intercommunication between a lot of mobile devices such as a PDA.

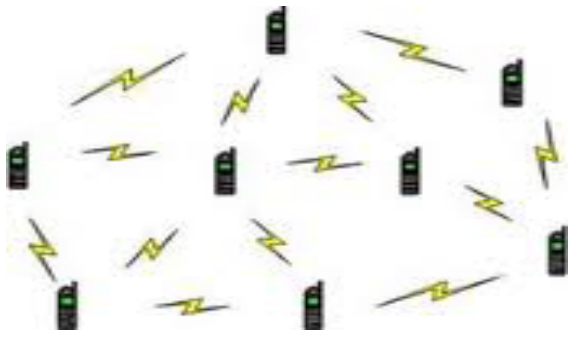

Figure 1.1 Mobile Ad hoc Network

The characteristics of MANETs are :

- Communication via wireless means
- Nodes act as both hosts and routers

- No centralized controller

- Dynamic network topology.

- Frequent routing updates.

- Can be set up anywhere.

- Energy constraints and limited security

Application Areas

- Military or police exercises

- Disaster relief operations.

- Mine site operations.

- Urgent Business meetings

\section{ROUTING PROTOCOLS}

Routing in mobile ad-hoc network, means transferring packets from source to destination, it is differ from traditional routing in a fixed network. Routing in MANET depends on many factors, which includes topology, selection of routers, initiation of request and available bandwidth. Mobile ad-hoc network routing protocols play a basic role in a possible future of existing devices. A protocol for MANET should be distributed in manner so that they increase its reliability, should be power-efficient and should consider its security [2],[3]

\subsection{Classification of Routing Protocols}

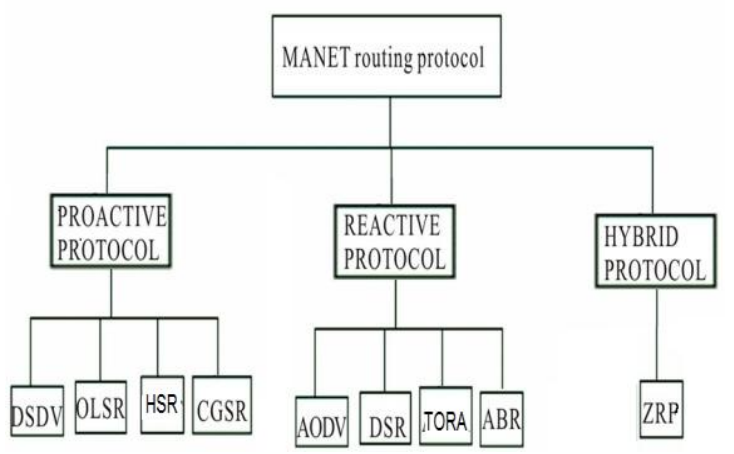

Figure 2.1

\subsection{Proactive Routing Protocol}

Proactive protocols continuously use the topology of the network by exchanging topological information among the network nodes. Thus, when there is a need for a route to a destination, such route information is available immediately. When the network topology changes too frequently, the cost of maintaining the network might be very high. If the network activity is low, the information about actual topology might even not be used. Every node 
maintains a list of destinations and updates its routes to them by analyzing periodic topology broadcasts from other nodes. When a packet arrives, the node checks its routing table and forwards the packet accordingly [2].

Proactive Routing Protocols are:

a) Global State Routing (GSR).

b) Hierarchical State Routing (HSR).

c) Destination Sequenced Distance Vector

Routing (DSDV).

A. Dynamic Destination-Sequenced Distance-Vector Routing Protocol (DSDV):

DSDV [3] is developed on the basis of Bellman-Ford routing algorithm with some modifications, that each node in the network keeps a routing table. Each routing table contains the list of all available destinations and the number of hops . Each table entry is tagged with a sequence number, which is originated by the destination node. In DSDV each node advertise its own routing table to its current neighbours. The advertisement is done either by broadcasting or by multicasting.

B. Global State Routing (GSR) : In this protocol [4], nodes exchange vectors of link states among their neighbors during routing information exchange. Based on the link state vectors, nodes maintain a global knowledge of the network topology and optimize their routing decisions locally. Functionally, this protocol is similar to DSDV, but it improves DSDV by avoids flooding of routing messages.

C. Hierarchical State Routing (HSR) : HSR [6] combines dynamic, distributed multilevel hierarchical clustering technique .In this network partition into several clusters where each elected cluster head at the lower level in the hierarchy becomes member of the next higher level.Each cluster head summarizes its own cluster information and passes it to the neighbouring cluster heads using gateways.

\subsection{Reactive Routing Protocols}

The reactive routing protocols are based on some sort of query-reply dialog. Reactive protocols proceed for establishing route(s) to the destination only when the need arises. They do not need periodic transmission of topological information of the network. A route search is needed for every new destination therefore the communication overhead is reduced at the expense of delay to search the route. Rapidly changing wireless network topology may break active route and cause subsequent route search

Reactive Routing Protocols

a) Ad hoc On-demand Distance Vector Routing (AODV).

b) Dynamic Source Routing (DSR).

c) Temporally Ordered Routing Algorithm (TORA).

\subsection{Hybrid Routing Protocols}

Often reactive or proactive feature of a particular routing protocol may not be enough, instead a mixture might yield better solution and as a result, routes are found quickly in the routing zone. eg ZRP. Hybrid routing algorithm is ideal for Zone Based Routing Protocol (ZRP).

\section{REACTIVE ROUTING PROTOCOLS \\ 3.1 Adhoc On-Demand Distance Vector Routing}

AODV stands for Ad-hoc On demand Distance Vector AODV is distance vector type routing where it does not involve nodes to maintain routes to destination that are not on active path. As long as end points are valid AODV does not play its part. Different route messages for each route created by destination node for any request to the nodes. A route with maximum sequence number is selected. To find a new route the source node sends RREQ message to the network till destination is reached or a node with fresh route is found. Then Route Reply is sent back to the source node. The nodes on active route communicate with each other by passing hello messages periodically to its immediate neighbour. If a node does not receive a reply then it deletes the node from list and sends Route Error to all the members in the active members in the route. AODV does not allow unidirectional link

\subsubsection{AODV Algorithms}

Route discovery : When a node wants to send data to another node in the network, it first to send a Route Request (RREQ) packet. RREQ where the record that is given by a source is to be used to find out a destination node. RREQ is a kind of flooding of the transfer mode, destination until they were received, a node can only be processed once on the same RREQ in order to avoid routing loop generation. All the nodes between the source and the destination of the RREQ will be passing a temporary record will be on the last hop of the RREQ via Path of information, when the destination of the RREQ received from different places, choose a shortest path, and to the source sent the direction of Route Reply (RREP). As the RREP of passing along the nodes on this path will be a record of the relevant information, when the RREP was sent to a sent RREQ the source the beginning, this section of the path from source to destination even been established, and thereafter source can use this route to send packets to the destination It is noteworthy that, AODV and DSDV routing table inside the same have also recorded destination sequence number, to avoid routing loop from occurring, but also to ensure the path recorded in the latest expression of the [7]

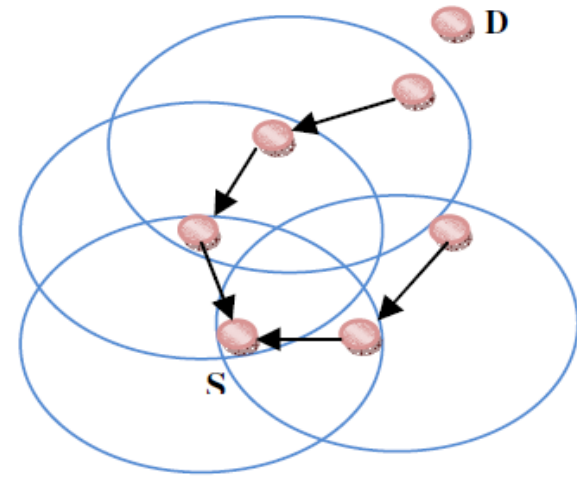

Fig 3.2.1 AODV: reverse path formation 


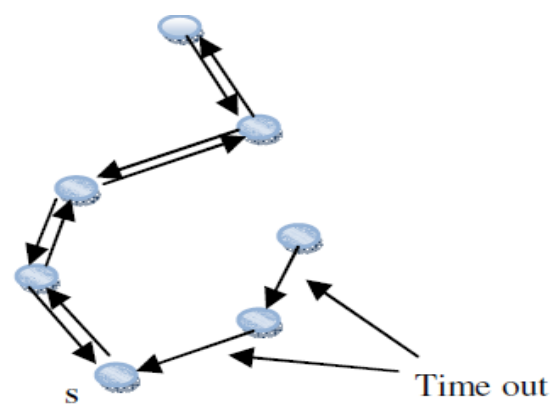

Fig 3.2.2 AODV: forward path formation

\section{Route maintenance}

Neighboring nodes with active routes periodically exchange hello messages[9] If a hop next link in the routing table fails, the active neighbors are informed The RERR (unsolicited RREP) indicates the unreachable destinations. The source performs a new route request when it receives a RERR.

\subsection{Dynamic Source Routing (DSR)}

This is an On-demand source routing protocol. In DSR the route paths are discovered after source sends a to a destination node in the ad-hoc network. The source node initially does not have a path to the destination when the first packet is sent. The DSR has two functions first is route discovery and the second is route maintenance

\subsubsection{DSR Algorithms}

a) Route discovery.

b) Route maintenance.

Assumptions:

a) $\mathrm{X}, \mathrm{Y}, \mathrm{Z}, \mathrm{V}$ and $\mathrm{W}$ form a network.

b) $\mathrm{X}$ is the source node

c) $\mathrm{Z}$ is the destination node.
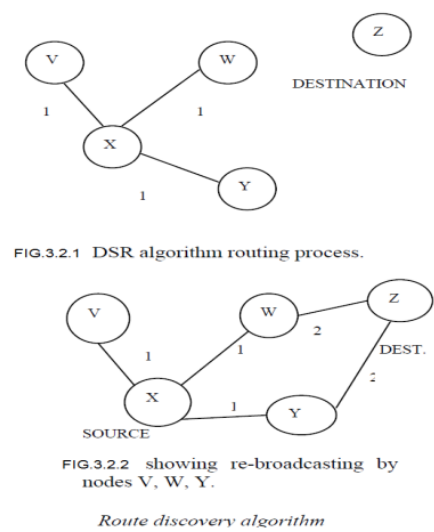

\section{Route discovery algorithm}

$\mathrm{X}$ broadcasts a Route Request Packet with the address of destination node $\mathrm{Z}$ The intermediate nodes $\mathrm{V}, \mathrm{W}, \mathrm{Y}$ receive the Route Request Packet from $X$, as shown in Fig1. The receiving nodes $\mathrm{V}, \mathrm{W}, \mathrm{Y}$ each append their own address to the Route Request Packet and broadcast the packet further as shown in Fig2. The destination node $\mathrm{Z}$ receives the Route Request packet. The Route Request packet now contains information of all the addresses of nodes on the path from the source node $\mathrm{X}$ to the destination node $\mathrm{Z}$. On receiving the Route Request Packet the destination node $\mathrm{Z}$ sends a reply called the Route Reply Packet to the source node $\mathrm{X}$ by traversing a path of addresses it has got from Route Request packet.

\section{Route Maintenance algorithm}

In DSR algorithm a link break is detected by a node along the path from node $\mathrm{X}$ to node $\mathrm{Z}$, in this case node $\mathrm{W}$. Then node $\mathrm{W}$ sends a message to source node $\mathrm{X}$ indicating a link break. In this case, node $\mathrm{X}$ can use another path like X-Y- Z or it must initiate another route discovery packet to the same destination node, in this case ' $Z$ '.

\subsection{Different caching techniques in DSR}

Each mobile host participating in the ad hoc network maintains a route cache in which it cache the source route that it has learned. There are several techniques for a node to learn \& store about the route, some of them are as follow. Running network interface in promiscuous mode. Reading the route information from data packets. Reading the routing information from Route Discovery packets. Reading the broken route information from Error packets.

\section{LITERATURE REVIEW}

Shivashankar et.al Proposed efficient power aware routing protocol which increases the network life time of MANET in compare to conventional power aware algorithm .Paper evaluated three adhoc network routing protocol EPAR,MTPR,DSR in different scale.This reduced more than $20 \%$ the total energy consumption \& decrease mean delay.

G.Vijay Kumar et.al Paper is a survey of active research work on routing protocols for MANET. Proactive routing protocols tend to provide lower latency than reactive, because they try to maintain routes to all the nodes in the network all the time.

Mahtab Singh et.al presented the simulation of routing protocols as a function of route maintenance parameters such as Active Route Timeout (ART) and Delete Period Constant $(\mathrm{DPC}=\mathrm{n})$ with moving nodes pairs in network Paper presented the Performance matrices evaluation and comparison of AODV routing protocol by varying Active Route Timeout (ART) and Delete Period Constant (n) at different Source -Destination (node) pair using QualNet 7.1

Claude Richard et.al paper showed that AODV protocol reduces the route discovery overhead by caching the route information for certain period of time after a connection expires. Paper focus on the AODV and optimal value to the length of time each node should keep the route information .Paper conducted extensive Simulation to better characterize the optimal value.

Charles E Perkins et.al presented paper on AODV routing protocols .AODV a novel algorithm for the operation of such adhoc networks Each Mobile Host operates as a specialized router and routes are obtained as needed ondemand with little or no reliance on periodic advertisements, new routing algorithm is quite suitable for a dynamic self starting network as required by users wishing to utilize adhoc networks AODV provides loopfree routes even while repairing brokenlinks Because the protocol does not require global periodic routing advertisements. 


\section{AODV AND DSR COMPARISION}

In this paper a comparison of AODV and DSR routing protocols has been evaluated. We have simulated. AODV and DSR performance using QUALNET 5.2 simulator QualNet is a commercial simulator that grew out of GloMoSim, which was developed at the University of California, Los Angeles and it is distributed by Scalable Network Technologies The QualNet simulator is C++ based. QualNet is a discrete event simulator and provides a ease of use and extensibility and power in terms of what scenarios can be simulated.

\section{Simulation Table 1}

\begin{tabular}{|c|c|}
\hline $\begin{array}{c}\text { Simulation } \\
\text { Parameter }\end{array}$ & Value \\
\hline Simulator & QualNet 5.2 \\
\hline Mobility model & Random way point \\
\hline Routing Protocols & AODV , DSR \\
\hline Traffic type & CBR \\
\hline Packet send rate & 4000 packets/s \\
\hline Data payload & $512 \mathrm{bytes} / \mathrm{packet}$ \\
\hline Node speed (min) & $1.0 \mathrm{~m} / \mathrm{s}$ \\
\hline Node speed (max) & $10 \mathrm{~m} / \mathrm{s}$ \\
\hline Transmission power & $10 \mathrm{dbm}$ \\
\hline Pause time & $1 \mathrm{sec}$ \\
\hline Packet interval & $4 \mathrm{sec}$ \\
\hline Simulation time & $900 \mathrm{sec}$ \\
\hline
\end{tabular}

Scenerio Table 2

\begin{tabular}{|l|l|l|l|}
\hline & Area size & Nodes & Link \\
\hline Scenerio1 & $1000 * 1000$ & 50 & 10 \\
\hline Scenerio2 & $1225 * 1225$ & 75 & 15 \\
\hline Scenerio3 & $1500 * 1500$ & 100 & 20 \\
\hline
\end{tabular}

The performance of AODV and DSR has been analyzed with varying number of

nodes $(50,75,100)$ and area size $(1000 * 1000$, $1225 * 1225,1500 * 1500)$. We measured packet delivery ratio, throughput, end to end delay. Based on simulation we generated the graphs. Graphs Shows various performance of AODV, DSR. Graphs have been analyzed using different values of nodes on $\mathrm{X}$-axis and of Received Throughput/Average End to End Delay/ PDR on Y-axis

1. Net Throughput: It indicates rate of communication per unit time. It is the ratio between the number of packets sends and number of packets received in particular given time

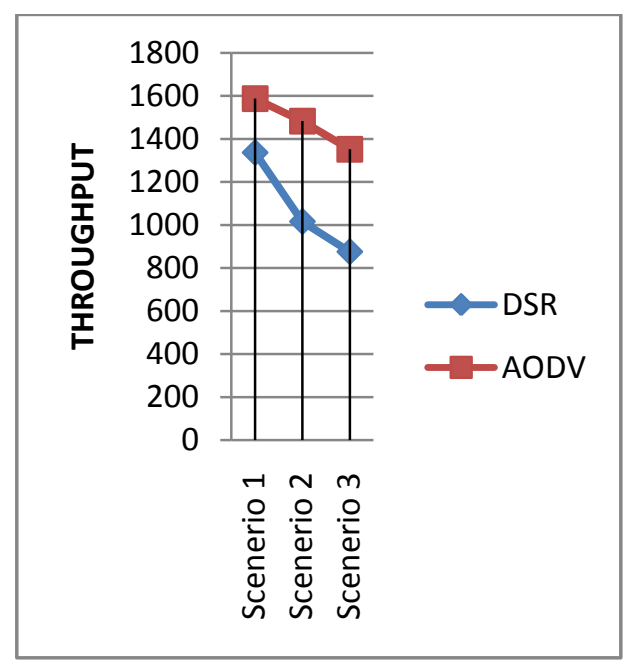

Fig 7.1 Net Throughput of AODV and DSR

2. Packet delivery ratio: The ratio of the number of data packets successfully delivered to the destinations to those generated by CBR sources. Packet delivery ratio $=(\text { Received packets/Sent packets })^{*} 100$

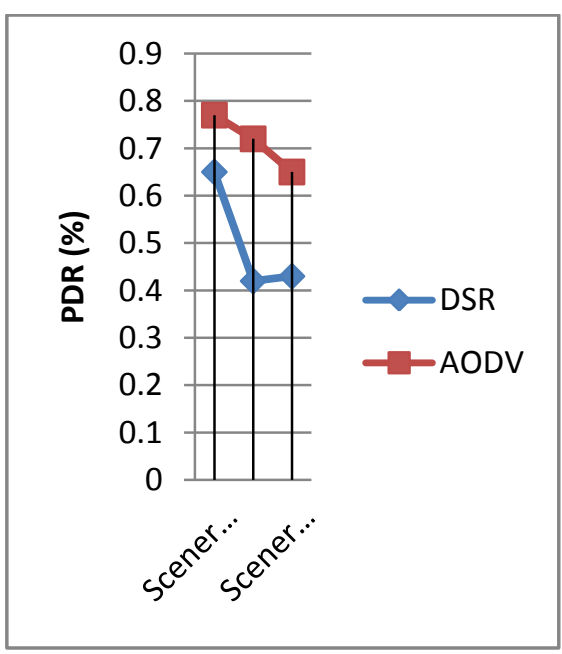

Fig7.2 Packet Delivery Ratio of AODV and DSR 
3. Average End to end delay of data packets: The average time from the beginning of a packet transmission at a source node until packet delivery to a destination.

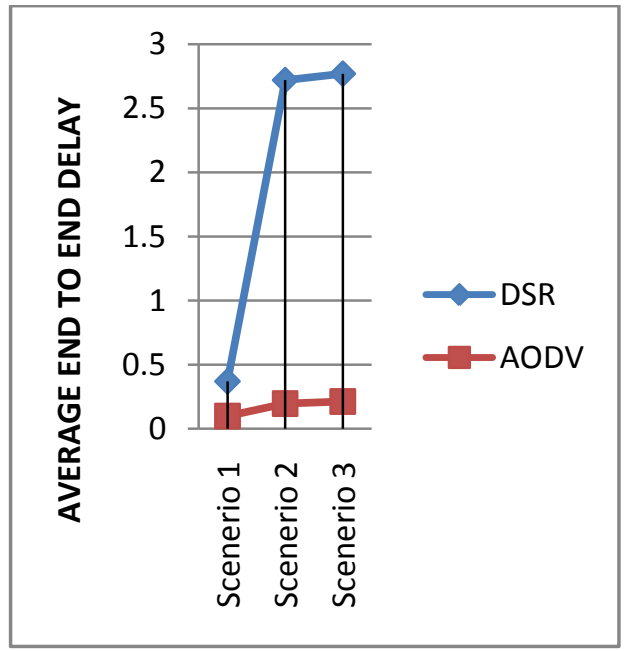

Fig7.3 Average End to End Delay of AODVand DSR

From fig 7.1 to fig 7.3 graph shows that by varying no of nodes AODV gives better result than the DSR in terms of Throughput, PDR and End to End delay.

\section{PROPOSED WORK}

Mobile ad hoc uses several routing protocols. The AODV routing protocol is one of several published reactive routing protocols and currently extensively researched, it builds and maintains route state based on two main processes. First is route discovery process allows to the source and destination nodes to establish a route using flooding a route request (RREQ) over the network by source, and the destination unicasts a route reply (RREP) to the source, all intermediate nodes store a route state Each node keep this state for a length of time given by the Active Route TimeOut (ART) value. Every time the route is used, the timer is reset to back to the ART. ART is the time at which route is consider valid. When a route is not used for some time, the nodes will remove the route state from the routing table. The time until the node removes the route states is called ART.[13]

Delete period constant (DPC) denotes the period after that an expired route is deleted. That expired route is deleted after delete period multiplied by the greater of Active Route Timeout (ART) or hello interval. Delete period $=$ Delete period constant $(\mathrm{n}) \times \max$ (active route timeout or hello interval), where delete period constant is having default value of $n=5 s$.

Different scenerio parameters are same as given in Table 1.

Simulation Table 3

\begin{tabular}{|l|l|}
\hline $\begin{array}{l}\text { Simulation } \\
\text { Parameter }\end{array}$ & \multicolumn{1}{|c|}{ Value } \\
\hline No of nodes & 50 \\
\hline Area size & $1000 * 1000 \mathrm{~m}$ \\
\hline $\begin{array}{l}\text { Transmission } \\
\text { power }\end{array}$ & $10 \mathrm{dbm}$ \\
\hline & \\
\hline
\end{tabular}

\begin{tabular}{|l|l|}
\hline Pause time & $1 \mathrm{sec}$ \\
\hline Packet Interval & $4 \mathrm{sec}$ \\
\hline Simulation time & $900 \mathrm{sec}$ \\
\hline
\end{tabular}

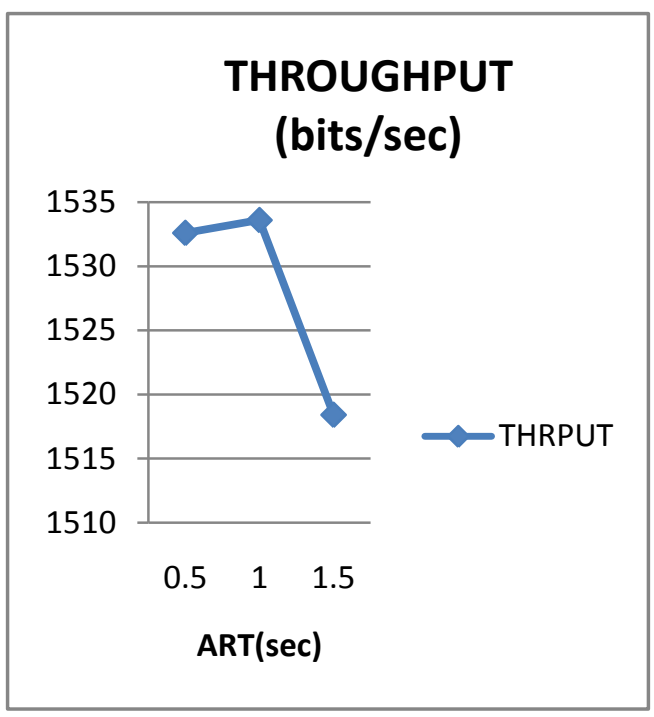

Fig7.4 Throughput at DPC $=5$

Fig 7.4 shows throughput of AODV is varying by the values of ART by $0.5,1,1.5$ at $\mathrm{DPC}=5$.here throughput is high at value of 0.5 and 1 and reduces at 1.5.

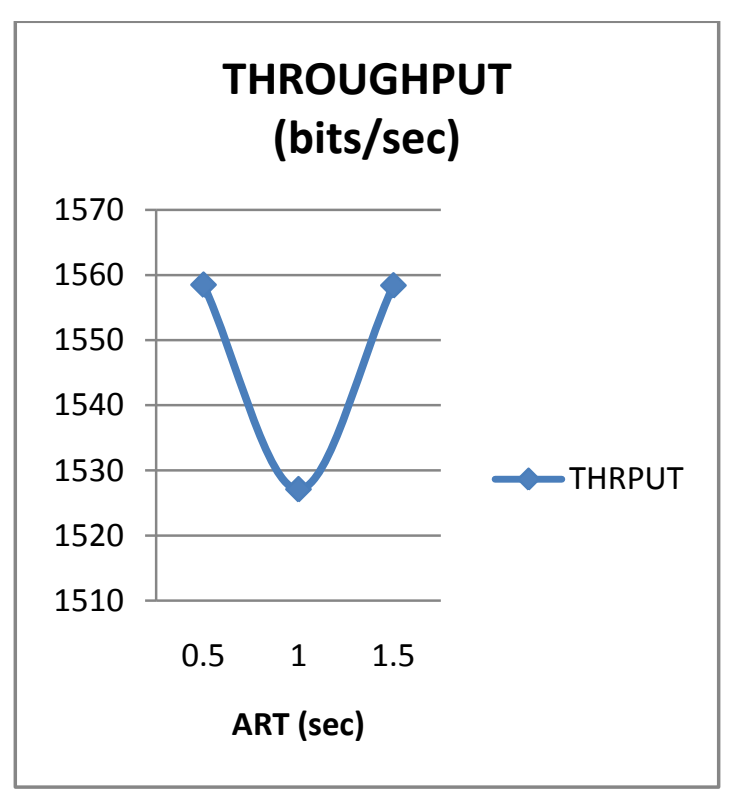

Fig 7.5 Throughput at DPC $=7$

Fig 7.5 shows that throughput increase and decrease alternately by ART values $(.5,1,15)$ at $\mathrm{DPC}=5$ 


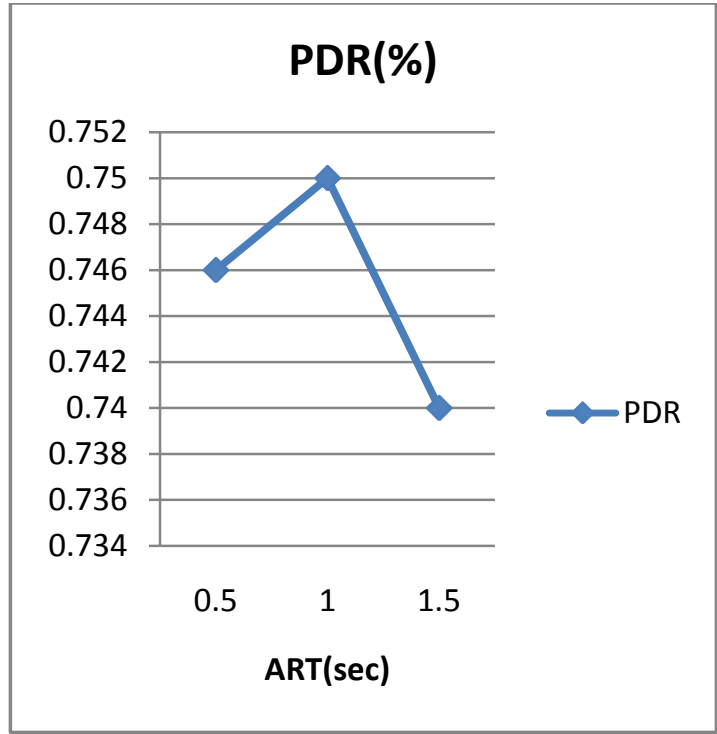

Fig 7.6 Packet Delivery Ratio at DPC =5

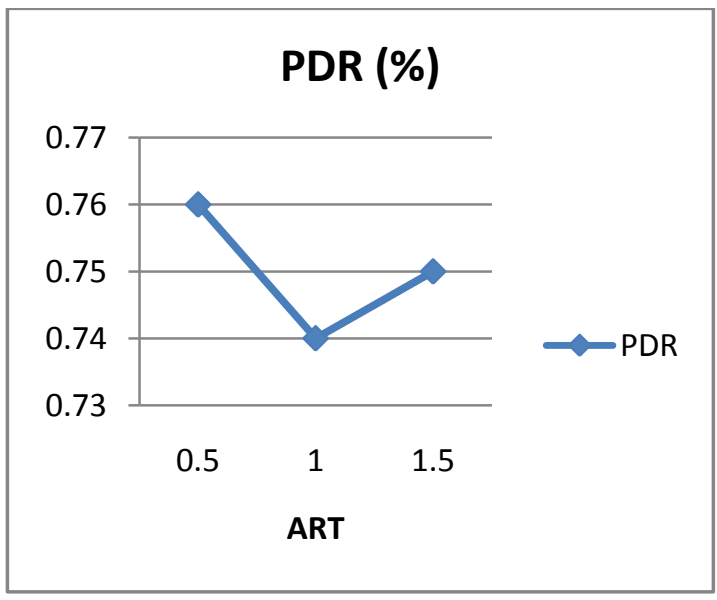

Fig 7.7 Packet Delivery Ratio at DPC=7

From figure 7.6 and 7.7 shows PDR of AODV varies by varying Active Route Timeout (ART) value by $0.5,1,1.5$ and at DPC is $n=5$ and $n=7$,so it difficult to conclude which value of ART is best. The

Throughput and PDR are varying with respect to varying values of ART and DPC . It is required to calculate the optimized value of ART \& DPC so that throughput will be high.

\section{CONCLUSION}

In this paper simulation of two MANET routing protocols AODV and DSR were evaluate with varying network size and node size . Performance metrics such as Average delay, Packet Delivery Ratio, Throughput are evaluated. This comparsion shows that Whatever be the scenario AODV exhibits a better behaviour as compared to DSR in terms of the packet delivery ratio and throughput AODV protocol was simulated as a function of route maintenance parameters such as Active Route timeout (ART) and Delete Period Constant (DPC). ART and DPC impact alot on AODV performance. Optimized value of ART and DC are required to calculate to improve the performance of AODV. Further calculation will be done in future.

\section{REFERENCES}

[1] G.Vijaya Kumar, Y.Vasudeva Reddyr , Dr.M.Nagendra" Current Research Work on Routing Protocols for MANET: A Literature Survey", (IJCSE) International Journal on Computer Science and Engineering Vol. 02, No. 03, 2010, pp 706-713.

[2] Natarajan Meghanathan and Levon Paul Judon," Improvement in Network Lifetime for On-Demand Routing in Mobile Ad hoc Networks Using either OnDemand Recharging or Transmission Power Control or Both", Computer and Information Science, Vol. 3 , No. 1, Feb. 2010, pp 3-11.

[3] Mahtab Singh, Sukriti Joshi, Rakesh Kumar, "Performance Matrices Evaluation and Comparison of AODV Routing Protocol by Varying ART and DPC at Different Source-Destination Pair Using Qualnet 7.1", International Journal of Advanced Engineering Research and Science (IJAERS) [Vol-1, Issue-1, June 2014]

[4] Hui Xu, Student Member, IEEE, Xianren $\mathrm{Wu}$ Member, IEEE, Hamid R. Sadjadpour, Senior Member, IEEE,and J. J. Garcia-Luna-Aceves, Fellow, IEEE," A Unified Analysis of Routing Protocols in MANETs ", IEEE Transactions on communications, vol 58, no3, march 2010.pp 912-922

[5] Neeraj tantubay, Dinesh Ratan Gautam and Mukesh Kumar Dhariwal, "A Review of Power Conservation in Wireless Mobile Adhoc Network (MANET)", IJCSI International Journal of Computer Science Issues, Vol. 8, Issue 4, No 1, July 2011.

[6] Seon Yeong,"An adaptive hello messagimg scheme for neighbour discovery in ON-Demand MANET routing protocols",IEEE communication letter vol 17,no 5, may 2013.pp 1040-1043

[7] Saleh Ali K.Al-Omari, Putra Sumari,"An over view of mobile adhoc networks for the existing protocols and the applications",International journal on application on graph theory in wireless adhoc network and sensor network (Graph Hoc) vol.2 march 2010.

[8] James pope and Robert simon,"CREST:An epochoriented routing protocols control plane for low power and lossy network", IEEE workshop on practical issues in bulding sensor network applications 2013.pp 128-136

[9] Vani.H \& Vadana.S,"Manet - Routing Technique", the international ljournal-RJSITM: Volume: 01, Number: 07, May-2012.

[10] N Vetrivelan,Dr A V Redddy,"Performance analysis of three routing protocols for varying MANET size",International Multiconference of Engineers and Computer march 2008.pp 1-5

[11] C.-K. Toh, "Evaluating the Communication Performance of an Ad Hoc Wireless Network",IEEE TRANSACTIONS ON WIRELESS COMMUNICATIONS, VOL. 1, NO. 3, JULY 2002.

[12] Shiva Shankar Suresh \& Guruswamy jayanthi," Designing energy routing protocol with power optimization in MANET", IEEE TRANSACTIONS ON EMERGING TOPICS IN COMPUTING, Vol 2,No 2, june 2014 . 
[13] Charles E Perkins and Elizabeth M Royer," Defining an Optimal Active Route Timeout for the AODV Routing Protocol",

[14] Claude Richard \& Charles E Perkins," Defining an Optimal Active Route Timeout for the AODV Routing Protocol"
[15] Archie Budhiraja \& Roopali Garg ,"A new local stability based routing mechanism for mobile ad-hoc networks", Proc. of the International Conference on Science and Engineering (ICSE 2011), Copyright (C) 2011 RG Education Society.pp 261-268 